\title{
Aspectos Microscópicos da Influência dos Processos de Esterilização em Pontas Diamantadas
}

\author{
Eduardo Carlos Bianchi ${ }^{\text {a*, Eraldo Jannone da Silva }}$, Fabio Andreassa Guedes Cezar ${ }^{\mathrm{a}}$, \\ Paulo Roberto de Aguiar, Ana Rita Rodrigues Bianchi ${ }^{\mathrm{b}}$, César Antunes de Freitas ${ }^{\mathrm{b}}$, \\ Heraldo Riehl ${ }^{\mathfrak{c}}$ \\ ${ }^{a}$ Universidade Estadual Paulista, Departamento de Engenharia Mecânica / Elétrica \\ C.P. 473, 17033-360 Bauru - SP, Brasil \\ ${ }^{\mathrm{b}}$ Universidade de São Paulo, Departamento de Dentística, Endodontia e Materiais \\ Dentários, 17043-101 Bauru - SP, Brasil \\ ${ }^{\mathrm{c}}$ Universidade Paulista-UNIP, Departamento de Materiais Dentários, \\ 17015-060 Bauru - SP, Brasil
}

Received: April 15, 2002; Revised: January 20, 2003

\begin{abstract}
This paper shows a study about the influence of type and number of sterilizations in the cutting ability of diamond points used in dentistry. As a result, the sterilization using the oven was the process, which didn't result in a decreasing in the cutting ability of the diamond points and, until the second sterilization, it resulted in a increasing of the cutting ability.
\end{abstract}

Keywords: sterilization, diamond points

\section{Introdução}

Nos tempos atuais, a odontologia está passando por algumas transformações no que diz respeito à biossegurança contra as doenças infectocontagiosas. Com o aparecimento da AIDS, a rotina no consultório em relação à proteção do cirurgião-dentista, do auxiliar, paciente e ambiente tem de ser modificada em vários aspectos (Corrêa, 1994). Dessa forma é de fundamental importância adotar medidas de controle de infecção nos consultórios odontológicos, usando todo o conhecimento sobre as técnicas de esterilização e desinfecção, as quais devem ser conhecidas para garantir a saúde do paciente e do profissional.

Se, por um lado, a adoção de procedimentos de esterilização e desinfecção é vital para garantir a realização de um atendimento odontológico seguro, estes procedimentos podem resultar em alterações no desempenho das pontas diamantadas, reduzindo a sua vida útil. Assim, o efeito de cada processo de esterilização no desempenho das mesmas deve ser conhecido, buscando-se obter um procedimento seguro aliado ao menor dano estrutural a ponta.

Neste trabalho é apresentado um estudo sobre os três principais tipos de esterilização de pontas odontológicas utilizados nos consultórios dentários. Através de procedi- mentos estatísticos de experimentação e de análise dos resultados obtidos nos ensaios das pontas, a sua capacidade de corte será determinada, em função dos métodos de esterilização utilizados, sendo ainda investigadas as alterações microscópicas ocorridas nas pontas decorrentes dos mesmos.

\section{Os Processos de Esterilização e Algumas Considerações sobre a Segurança nos Consultórios Dentários}

Os profissionais da área odontológica expõem-se frequientemente a infecções por diversos tipos de vírus, como o da hepatite, AIDS etc., ao entrar em contato com sangue, exudatos ou saliva (Ministério da Saúde, 1994; Marques, 1997). Há, também, a possibilidade de contrair a infecção ao picar-se com instrumentos contaminados ou sujar-se com sangue em uma região onde a pele apresente uma solução de continuidade (Marques, 1997).

A doença pode também se transmitir por salpicadas nos olhos e boca, e não se deve excluir a possibilidade de contaminação por inalação de finas gotículas de aerossol, formadas pelo sistema de refrigeração dos aparelhos odontológicos de alta rotação (Corrêa, 1994; Marques, 1997).

*e-mail: bianchi@feb.unesp.br 
Para reduzir o risco de infecção, todos os membros do consultório devem seguir com atenção todas as normas de segurança.

$\mathrm{Na}$ área da saúde, não há nenhuma atividade que apresente um quadro tão heterogêneo de detalhes com vistas ao controle de infecção quanto a Odontologia, o que pode dificultar a tomada de decisões em relação aos cuidados quanto à esterilização ou desinfecção de superfícies ou instrumentos. As dificuldades poderão ser eliminadas ou extremamente reduzidas, se o profissional, independentemente de sua especialidade, distinguir o ambiente de atuação e o risco potencial de transmissão dos instrumentos e materiais utilizados.

Dentre os processos de esterilização, a por processo físico pode ser efetuada através de vapor saturado sob pressão e calor a seco (FOB, 2000).

O processo por vapor saturado sob pressão é o processo que oferece maior segurança e economia. Pode ser realizado em autoclave convencional horizontal ou autoclave a alto vácuo. Usar exposição por 30 (trinta) min a uma temperatura de $121^{\circ} \mathrm{C}$, em autoclaves convencionais (uma atmosfera de pressão). Usar exposição por 15 (quinze) min a uma temperatura de $132{ }^{\circ} \mathrm{C}$, em autoclaves convencionais (uma atmosfera de pressão). Usar exposição por 04 (quatro) min a uma temperatura de $132{ }^{\circ} \mathrm{C}$, em autoclave de alto vácuo.

$\mathrm{Na}$ esterilização por calor seco, este é gerado em estufa elétrica (forno de Pasteur). É de uso limitado, pois sua penetração e distribuição dentro da câmara não se fazem de maneira uniforme, além do que, o processo requer um tempo de exposição mais prolongado a altas temperaturas, o que é inadequado para certos materiais, tais como tecidos e borrachas. O tempo e temperatura utilizados na Central de Esterilização, e recomendados para esterilização a seco são: $2 \mathrm{~h}$ à $170^{\circ} \mathrm{C}$, respectivamente. A Res. SS - 374 recomenda $1 \mathrm{~h}$ a $170{ }^{\circ} \mathrm{C}$ e $2 \mathrm{~h}$ a $160^{\circ} \mathrm{C}$. Recomenda-se o prazo de 7 (sete) dias de validade para os artigos esterilizados por processo físico (Resolução SS-374, de 15/12/95).

A Esterilização química é um processo de longa duração (de 8 a 18 h) no qual se consegue a destruição de todas as formas de vida através do uso de agentes químicos de- signados como esterilizantes. Entre os agentes químicos esterilizantes estão os aldeídos (glutaraldeído e formaldeído) e o óxido de etileno.

O Glutaraldeído é um dialdeído, que pode se apresentar pronto para o uso. Em pH ácido, necessita ativação pelo bicarbonato de sódio, para exibir atividade esterilizante. O glutaraldeído ativado sofre polimerização em $\mathrm{pH}$ alcalino, inativando-se após 14 dias, quando seu pH for 8,5, ou após 28 dias, em pH 7,5. É esterilizante (8 a 10 h) e desinfetante de alto nível (30 min). É indicado para a esterilização de artigos críticos e semi-críticos termo-sensíveis; desinfecção de alto nível e descontaminação. As vantagens são: penetra no sangue, pus e restos orgânicos; não ataca material de borracha ou plástico. As desvantagens são: apresenta toxicidade cutânea, celular e inalatória; libera vapores tóxicos, razão para se evitar o processamento de materiais em salas mal ventiladas, em recipientes sem tampa ou com vazamentos; aconselha-se o uso de máscaras com camada de carvão ativado para diminuir o efeito tóxico, quando em manipulação freqüente; é alergênico; não pode ser utilizado em superfícies; sua atividade corrosiva aumenta com a diluição; seu tempo de reutilização varia com a biocarga; pode ser retido por materiais porosos, daí exigir enxagüe rigoroso, para evitar seus resíduos tóxicos.

As desvantagens da esterilização química são: o material não pode permanecer estéril, uma vez que é esterilizado não-embalado. Não existe teste biológico para comprovar a esterilidade.

Sempre que for ser realizado um procedimento de esterilização ou desinfecção de material, a pessoa que for manipular os instrumentos deve fazer uso dos equipamentos de proteção individual (EPI), segundo as normas internacionais de segurança. Para a sua própria proteção, o profissional de odontologia deve, durante o tratamento do paciente, fazer uso de: máscaras ou filtro; óculos protetores; luvas de borracha e materiais descartáveis.

A Tabela 1 indica os equipamentos de proteção individual necessários para a realização dos procedimentos de esterilização por estufa, autoclave e com solução de glutaraldeído a $1 \%$.

Tabela 1. Equipamentos de proteção individual (EPI) para a realização de acordo com o procedimento de esterilização em curso (Marques, 1997).

\begin{tabular}{lll}
\hline Método / Produto & Toxicidade & \multicolumn{1}{c}{ EPI necessário } \\
\hline Autoclave & Não existe & Luva de amianto de cano longo. \\
Estufa & Não existe & Luva de amianto de cano longo. \\
& Tóxico por inalação, contato & Máscara com filtro químico, \\
Glutaraldeído & com a mucosa ou pele. & Óculos, \\
& Carcinogênico em potencial & Luvas de borracha, \\
& & Avental impermeável. \\
\hline
\end{tabular}




\section{Metodologia dos Ensaios}

\subsection{Descrição do Ensaio de Retificação Utilizado}

Para o estudo comparativo da influência dos processos de esterilização no desempenho de das pontas diamantadas foram fabricadas pontas recobertas com grãos superabrasivos de diamantes naturais e sintéticos (granulometria D120/140), conforme dimensões apresentadas na Fig. 1. Utilizou-se o processo de eletrodeposição de níquel para a fixação dos grãos de diamante na parte ativa da haste metálica, cujo comprimento útil de utilização é de $12 \mathrm{~mm}$. O controle da distribuição dos grãos de diamante ao longo deste comprimento útil depende das variáveis do processo produtivo, tais como: tamanho médio dos grãos, intensidade de corrente galvânica, dentre outros. Estas pontas foram ensaiadas em um banco de ensaio composto por três partes básicas: mecânica, eletrônica e computacional.

A parte mecânica do banco de ensaios é constituída de uma máquina retificadora plana, marca Reti Lite, com $600 \mathrm{~mm}$ de curso longitudinal, $400 \mathrm{~mm}$ de curso transversal e com $400 \mathrm{~mm}$ de altura entre o rebolo e a mesa. O movimento transversal da mesa é controlado por um motor de corrente contínua com velocidade mínima de $20 \mathrm{~mm} / \mathrm{min}$ e máxima de $500 \mathrm{~mm} / \mathrm{min}$. O movimento longitudinal da mesa é feito por meio de um sistema hidráulico.

No cabeçote da retificadora foi fixada a caneta odontológica marca DENTEC, com micromotor de corrente contínua de $31 \mathrm{~V}$ de tensão de alimentação, apresentando rotação máxima de $24.000 \mathrm{rpm}$, responsável pela rotação das pontas diamantadas. A fixação da peça ao cabeçote foi feita com o auxílio de uma peça de nylon, elaborada para que a caneta não se danifique durante o processo de usinagem. Sobre a mesa da máquina retificadora, utilizouse uma morsa para a fixação dos corpos-de-prova.

A parte eletrônica do banco de ensaios é responsável pela aquisição dos valores de tensão e corrente elétrica que

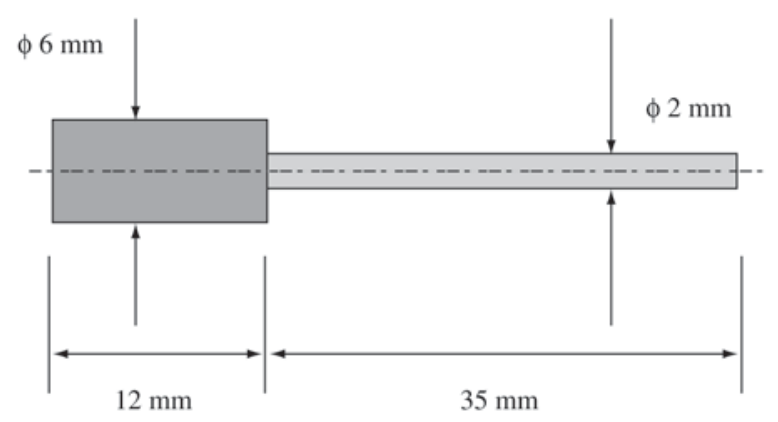

Figura 1. Esboço da ponta diamantada utilizada nos ensaios. agem sobre o micromotor e conversão desses valores em intensidades compatíveis com a placa de aquisição A/D. A conversão de valores pela parte eletrônica da montagem consistiu na conversão do valor de corrente consumida pelo micromotor em tensão compatível com a placa de aquisição A/D; conversão do valor de tensão aplicada sobre o micromotor em valores compatíveis com a placa de aquisição A/D e conversão da freqüência de rotação do eixo do micromotor em tensão compatível com a placa de aquisição A/D.

Utilizando-se o software de aquisição de dados LabVIEW, o valor da força tangencial de corte $\left(\mathrm{F}_{\mathrm{t}}\right)$ da ponta pode ser obtida pela equação:

$$
\mathrm{T}=\mathrm{F}_{\mathrm{t}} \times\left(\mathrm{d}_{\mathrm{s}} / 2\right)
$$

onde ds é o diâmetro externo da ponta e T é o torque aplicado pelo micromotor que é obtido pela equação:

$$
\mathrm{T}=(\mathrm{I} \times \mathrm{V} \times 60) /(2 \times \mathrm{p} \times \mathrm{n})
$$

sendo I e V são os valores de corrente e tensão elétrica aplicados no micromotor da caneta odontológica, e n o número de rotações no eixo do micromotor.

Logo, dois dos valores para a determinação da intensidade do torque instantâneo (T) são variáveis diretamente conhecidas, pois os valores de corrente elétrica instantânea (I) e tensão elétrica instantânea (V) são transformados pela placa $\mathrm{A} / \mathrm{D}$ em sinais digitais e enviados ao software.

O número de rotações na unidade de tempo (n) no eixo não é obtido diretamente pela montagem eletrônica, devido as dificuldades físicas para a instalação de um medidor de rotação como, por exemplo, um "encoder" no eixo árvore da caneta. Com a utilização dos valores de tensão e corrente elétrica instantâneos é possível determinar a rotação instantânea do eixo árvore do micromotor com a utilização de um modelo matemático, desenvolvido por Aguiar e Rotta (1990), que simula o funcionamento do micromotor de corrente contínua da caneta odontológica.

Como recomendado pela ADA, escolheu-se o vidro (temperado plano, tipo cristal) como material para a confecção dos corpos-de-prova, pois esse apresenta características semelhantes àquelas do esmalte dentário, sendo porém mais uniforme, fazendo com que se preste, de modo todo especial, para o controle da eficiência de corte de grãos de diamante (Vaz, J.C. et al., 1981). Tal material foi caracterizado como apresentando dureza média SPB de 3,98, após jateamento com quartzo de granulação 20/30 e pressão de 19,1 psi $\left(1,34 \mathrm{kgf} / \mathrm{cm}^{2}\right)$, por $30 \mathrm{~s}$, em uma área cilíndrica delimitada de $0,785 \mathrm{~cm}^{2}$. As dimensões dos corpos - de prova são $155 \mathrm{~mm} \times 90 \mathrm{~mm} \times 8 \mathrm{~mm}$. O corte foi realizado no comprimento de corte foi de $90 \mathrm{~mm}$.

As pontas diamantadas foram submetidas a ensaios de 
retificação do tipo tangencial plana de mergulho. Nesses ensaios a velocidade de deslocamento transversal da mesa da máquina retificadora foi $0,0055 \mathrm{~m} / \mathrm{s}$, a velocidade de corte da ponta diamantada $7,1 \mathrm{~m} / \mathrm{s}$ e a penetração da ponta diamantada no corpo-de-provas foi de $400 \mu \mathrm{m}$ por passada. Estes valores foram mantidos constantes para a realização de todos os ensaios experimentais.

Nos ensaios realizados, o principal parâmetro em estudo nas pontas diamantadas foi o número de passadas de usinagem, o que representa a capacidade da ponta em remover material, ou seja, desempenhar seu papel de instrumento de corte. As pontas diamantadas foram solicitadas até o momento em que, por elevação excessiva do torque, ocorria o travamento do eixo do micromotor (fim de ensaio) que, neste caso correspondeu a uma força tangencial de corte de 6,5 N. Conseqüentemente, como o comportamento de cada ponta diamantada foi distinto, o volume de material removido (determinado pelo produto entre o número de passadas da ponta sobre o corpo-de-prova e a área superficial deste) diferenciou para cada ensaio realizado.

\subsection{O processo de Esterilização}

Inicialmente foram realizados quatro ensaios com duas pontas, sem que essas tivessem sofrido esterilização. Dessa forma, estabeleceu-se uma referência da capacidade de corte de uma ponta diamantada nova e sem esterilização.

Posteriormente, para cada tipo de esterilização, seguiuse o procedimento descrito abaixo:

1) Esterilizou-se um lote de seis pontas, o que correspondeu à primeira esterilização. Desse lote foram retiradas duas pontas, as quais já estavam prontas para ensaio;

2) As quatro pontas restantes foram submetidas à nova esterilização (segunda esterilização). Ao término de tal etapa, foram retiradas mais duas pontas para a realização dos ensaios;

3) Finalmente, as duas pontas que ainda não foram utilizadas sofreram a terceira esterilização e, posteriormente, seguiram aos ensaios.

Os parâmetros de esterilização são apresentados na Tabela 2 .

Sempre, que um grupo de pontas acabava de sofrer todas os previstos ciclos de esterilização, cada ponta do grupo recebia a nomenclatura para o ensaio.

Tabela 2. Tempo e temperatura utilizados nos processos de esterilização.

\begin{tabular}{lcc}
\hline Processo & Tempo $(\mathrm{min})$ & Temperatura $\left({ }^{\circ} \mathrm{C}\right)$ \\
\hline Estufa & 60 & 170 \\
Autoclave & 15 & 110 \\
Químico & 60 & não se aplica \\
\hline
\end{tabular}
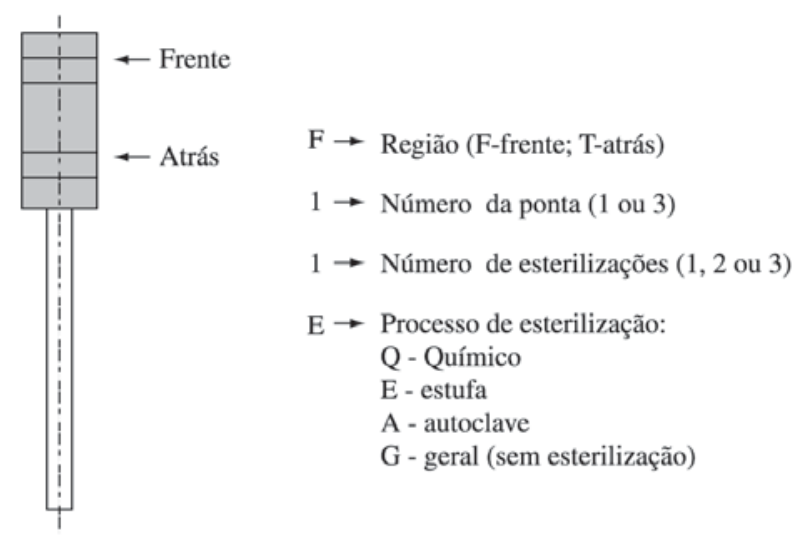

Figura 2. Nomenclatura das pontas diamantadas para os ensaios.

\subsection{Nomenclatura dos Ensaios}

A nomenclatura para a identificação das pontas ensaiadas foi desenvolvida com a finalidade de proporcionar uma rápida compreensão do tipo de esterilização, número de esterilizações, número da ponta (duas pontas por etapa de esterilização) e região da ponta utilizada para o corte. Dessa forma, sempre foi possível manter o controle das pontas já utilizadas e, posteriormente, selecionar as pontas que melhor representariam um grupo em um estudo por microscopia.

A Fig. 2 apresenta os parâmetros para a nomenclatura das pontas diamantadas.

\subsection{Seleção das Pontas para o Estudo por Microscopia}

Ao término dos ensaios de corte, o estudo microscópico das pontas diamantadas mostrou-se necessário para um melhor entendimento da fenomenologia de desgaste.

A microscopia é um estudo que consome, para cada espécime estudado, tempo razoavelmente longo. Por esses motivos, no presente trabalho, optou-se por uma avaliação amostral que indicasse de forma rápida e objetiva a possível fenomenologia de desgaste das pontas diamantadas. Como amostras foram escolhidas as pontas diamantadas que melhor se enquadraram aos valores obtidos pelo cálculo estatístico dos resultados de ensaio.

\section{Resultados e Discussão}

Para melhor apresentação dos resultados obtidos nos ensaios experimentais, são apresentados, na Tabela 3 o número de passadas alcançado por cada uma das pontas diamantadas ensaiadas, em função do tipo de esterilização utilizada (sem esterilização, estufa, autoclave e químico) e em função do número de esterilizações efetuadas dentro de um mesmo processo (1, 2 ou 3 esterilizações), a média de 
Tabela 3. Resultados obtidos para as pontas ensaiadas.

\begin{tabular}{lccccc}
\hline \multicolumn{2}{c}{ Sem Esterilização } & \multicolumn{2}{c}{ Estufa 1 esterilização } & \multicolumn{2}{c}{ Estufa 2 esterilizações } \\
\hline Ensaio & № de Passadas & Ensaio & № de Passadas & Ensaio & № de Passadas \\
$G 01 F$ & 211 & $E 11 F$ & 200 & $E 21 F$ & 263 \\
$G 01 T$ & 120 & $E 11 T$ & 303 & $E 21 T$ & 208 \\
$G 02 F$ & 191 & $E 12 F$ & 223 & $E 22 F$ & 113 \\
$G 02 T$ & 158 & $E 12 T$ & 233 & $E 22 T$ & 302 \\
Média Pop. & 170 & Média Pop. & 240 & Média Pop. & 222 \\
Desv. Padrão & 39,86 & Desv. Padrão & 44,37 & Desv. Padrão & 81,97 \\
\hline
\end{tabular}

\begin{tabular}{lccccc}
\hline \multicolumn{2}{c}{ Estufa 3 } & esterilizações & \multicolumn{2}{c}{ Químico 1 esterilização } & \multicolumn{2}{c}{ Químico 2 esterilizações } \\
\hline Ensaio & № de Passadas & Ensaio & № de Passadas & Ensaio & № de Passadas \\
$E 31 F$ & 157 & $Q 11 F$ & 98 & $Q 21 F$ & 72 \\
$E 31 T$ & 124 & $Q 11 T$ & 102 & $Q 21 T$ & 70 \\
$E 32 F$ & 98 & $Q 12 F$ & 120 & $Q 22 F$ & 67 \\
$E 32 T$ & 161 & $Q 12 T$ & 145 & $Q 22 T$ & 60 \\
Média Pop. & 135 & Média Pop. & 116 & Média Pop. & 67 \\
Desv. Padrão & 29,72 & Desv. Padrão & 21,42 & Desv. Padrão & 5,25 \\
\hline
\end{tabular}

\begin{tabular}{lccccc}
\hline \multicolumn{2}{c}{ Químico 3 esterilizações } & \multicolumn{2}{c}{ Autoclave 1 esterilização } & \multicolumn{2}{c}{ Autoclave 2 esterilizações } \\
\hline Ensaio & № de Passadas & Ensaio & № de Passadas & Ensaio & № de Passadas \\
$Q 31 F$ & 79 & $A 11 F$ & 52 & $A 21 F$ & 73 \\
$Q 31 T$ & 50 & $A 11 T$ & 52 & $A 21 T$ & 71 \\
$Q 32 F$ & 64 & $A 12 F$ & 71 & $A 22 F$ & 62 \\
$Q 32 T$ & 48 & $A 12 T$ & 77 & $A 22 T$ & 62 \\
Média Pop*. & 60 & Média Pop. & 63 & Média Pop. & 67 \\
Desv. Padrão & 14,38 & Desv. Padrão & 12,94 & Desv. Padrão & 5,83 \\
\hline
\end{tabular}

* Valores da média já com os arredondamentos.

\begin{tabular}{lc}
\hline \multicolumn{2}{c}{ Autoclave 3 esterilizações } \\
\hline Ensaio & № de Passadas \\
A31F & 71 \\
A31T & 75 \\
A32F & 60 \\
A32T & 64 \\
Média Pop. & 67 \\
Desv. Padrão & 6,76 \\
\hline
\end{tabular}

passadas obtida, bem como o desvio-padrão de cada um dos grupos de pontas testadas.

Pode-se notar, em todos os ensaios, a dispersão de alguns resultados obtidos para um mesmo tipo e quantidade de esterilizações. A dificuldade em se assegurar a homogeneidade no processo de fabricação, por se tratar de um processo de eletrodeposição de níquel em uma matriz metálica, não confere as mesmas qualidades para todas as pontas diamantadas, mesmo que essas pertençam a um

mesmo lote de fabricação. Sempre ocorrem diferenças relacionadas ao espaçamento médio entre os grãos e a densidade de grãos abrasivos de diamante, dentre outros.

Como grupo de controle, foram ensaiadas pontas diamantadas que não sofreram nenhum tipo de esterilização (Grupo "Sem Esterelização"). A Fig. 3a e 3b apresentam a visualização microscópica da superfície das pontas diamantadas sem esterilização, antes e ao final do ensaio, respectivamente.

A Fig. 4 apresenta o número médio de passadas obtidas para as pontas diamantadas testadas, em função do tipo de esterilização empregado e do número de esterilizações efetuadas (considerando-se o grupo de controle como sendo as pontas diamantadas que não sofreram nenhum tipo de esterilização). A média de passadas do grupo de controle é representada pelo ponto correspondente no eixo y "número de passadas", ao ponto "zero" no eixo x "número de esterilizações" do gráfico da Fig. 4.

Analisando-se o gráfico da Fig. 4, nota-se claramente uma melhora na capacidade de corte das pontas diamantadas 


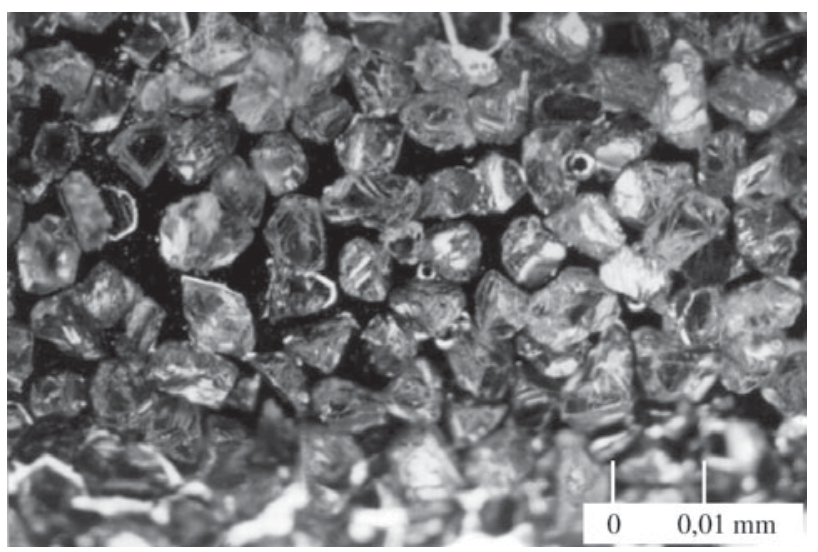

a)

Figura 3. Ponta diamantada sem esterilização.

submetidas a uma e a duas esterilizações em estufa em relação ao grupo de controle. Porém, houve uma queda na capacidade de corte das pontas diamantadas submetidas três repetidas vezes a esse processo de esterilização.

A esterilização em estufa processa-se em ambiente seco, a uma temperatura de $170{ }^{\circ} \mathrm{C}$, durante $60 \mathrm{~min}$. Sabe-se que a ancoragem dos diamantes ao "blank" metálico ocorre devido à fixação por eletrodeposição de níquel. O níquel, por ser um material formado por cristais monoatômicos, ao ser aquecido por tempo prolongado e resfriado ao ambiente, sofre um acomodamento atômico que aproxima seus átomos, aumentando a sua dureza. Isto produz uma melhor ancoragem para os grãos de diamante, os quais permanecem retidos ao "blank" até mesmo em forças tangenciais de corte superiores àquelas suportadas por diamantes em pontas diamantadas que não foram submetidas a esse processo térmico.

Porém, o aumento de dureza da camada de níquel provoca concentração de tensões nas regiões de contato com os grãos de diamante. Quando repete-se a esterilização em estufa pela terceira vez consecutiva, a concentração de tensões é muito elevada e a camada de níquel rompe-se por fadiga ao ser submetido aos esforços de corte.

Esse mecanismo de desgaste das pontas diamantadas submetidas ao processo de esterilização por estufa é notado claramente na observação da seqüência de fotos apresentadas na Fig. 5 as quais apresentam a superfície da ponta usinada após a realização dos ensaios em estufa, após uma, duas e três esterilizações, respectivamente referentes aos ensaios E12F, E21F e E31F.

Nota-se nas fotos das micrografias das pontas que foram submetidas a três esterilizações o arrancamento da camada de níquel quando da perda do grão de diamante. Nas pontas esterilizadas uma ou duas vezes percebe-se que os grãos de diamante ficaram presos por mais tempo, o que

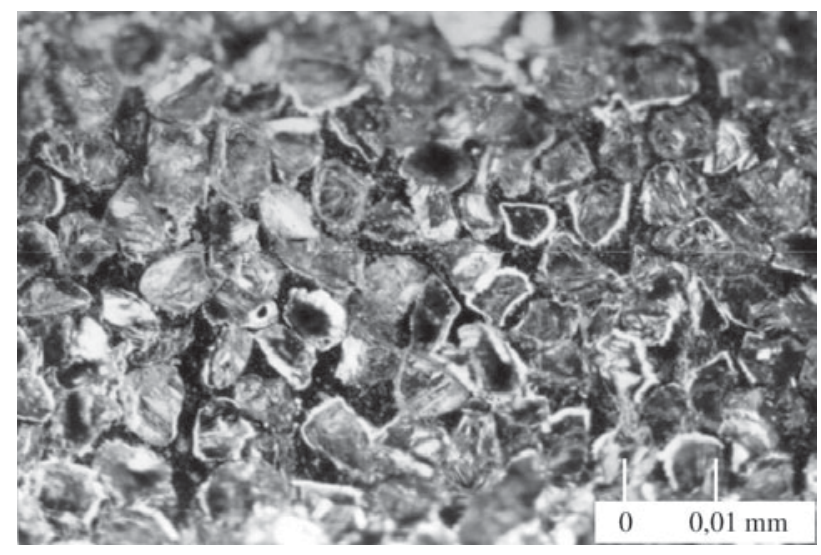

b)

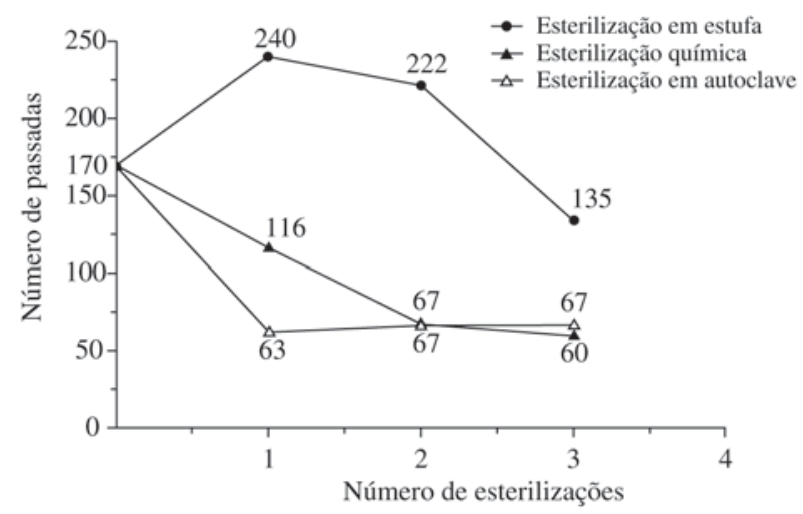

Figura 4. Número médio de passadas obtidas para as pontas diamantadas ensaiadas, em função do tipo e número de esterilizações efetuadas.

possibilitou microfraturas dos grãos e, assim, a manutenção da capacidade de corte por mais tempo.

Observando-se o gráfico apresentado na Fig. 4, percebe-se claramente que o processo de esterilização em autoclave provocou a rápida degradação das pontas diamantadas. Logo na primeira esterilização, as pontas diamantadas perderam a sua capacidade de corte. Esta apresentou pequeno acréscimo na segunda esterilização e estabilizou-se na terceira.

O processo de esterilização em autoclave, o qual consiste em submeter à ponta diamantada a uma temperatura de $110{ }^{\circ} \mathrm{C}$, durante $20 \mathrm{~min}$, em uma atmosfera saturada de vapor d'água, causa uma maior dilatação térmica no níquel do que nos grãos de diamante, já que este possui menor dilatação térmica. Desta forma, quando as pontas são submetidas ao aumento de temperatura abre-se uma passagem 
entre o grão de diamante e a ancoragem de níquel, possibilitando a infiltração de vapor d'água. Quando do resfriamento, esse vapor se condensa na região entre o grão de diamante e a camada de níquel provocando corrosão dessa última e, dessa forma, reduz-se a capacidade de retenção dos grãos de diamante.

Esse mecanismo de desgaste das pontas diamantadas submetidas ao processo de esterilização em autoclave é notado claramente na observação da sequiência de fotos apresentadas na Fig. 6, as quais apresentam a superfície da ponta usinada após a realização dos ensaios em autoclave, após uma, duas e três esterilizações, respectivamente referentes aos ensaios A11F, A22F e A31F. Nestas imagens, nota-se um desgaste maior das pontas, com maior liberação de grãos $(\mathrm{A} 11 \mathrm{~F})$.

Da análise do gráfico da Fig. 4, percebe-se a progressiva diminuição na capacidade corte das pontas de diamantadas a medida que essas são submetidas repetidas vezes à esterilização química em solução de glutaraldeído a $1 \%$.

O glutaraldeído se torna um agente esterilizante mais potente à medida em que é aumentada sua concentração na solução. Porém, aumentando-se essa concentração, elevase também sua ação corrosiva (Napier e Senatore, 1997).

A diminuição da capacidade de corte das pontas submetidas a esse tipo de esterilização química deve-se ao fato do glutaraldeído ser uma substância corrosiva.

A observação da Fig. 7, que apresenta os resultados dos ensaios micrográficos das pontas diamantadas submetidas à esterilização por glutaraldeído, após uma, duas e três esterilizações, respectivamente referentes aos ensaios A11F, $\mathrm{A} 22 \mathrm{~F}$ e $\mathrm{A} 31 \mathrm{~F}$, demonstram que a perda de grãos de diamante foi mais acentuada nas pontas diamantadas que sofreram repetidas vezes mais esterilizações por glutaraldeído
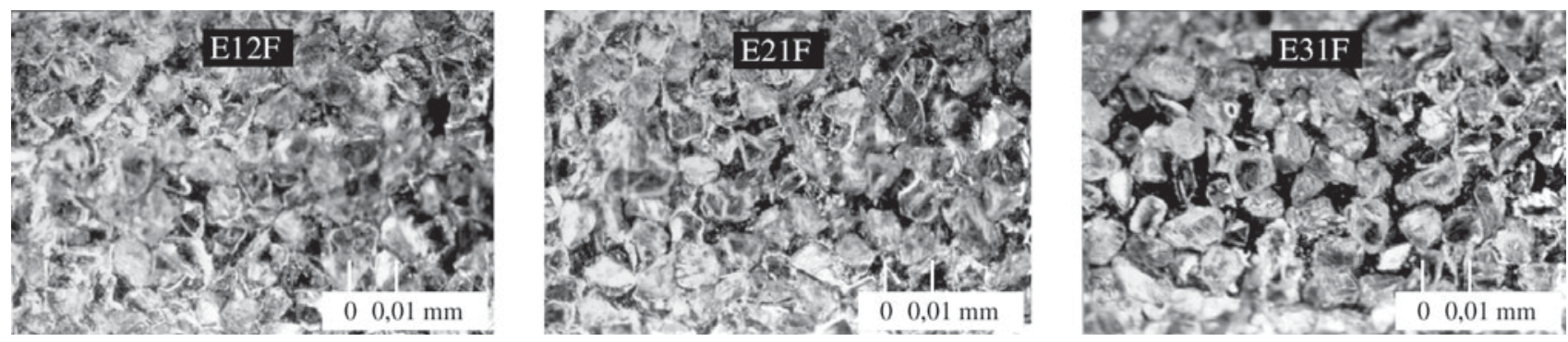

Figura 5. Superfície da ponta usinada após a realização dos ensaios, após uma, duas e três esterilizações em estufa, respectivamente.
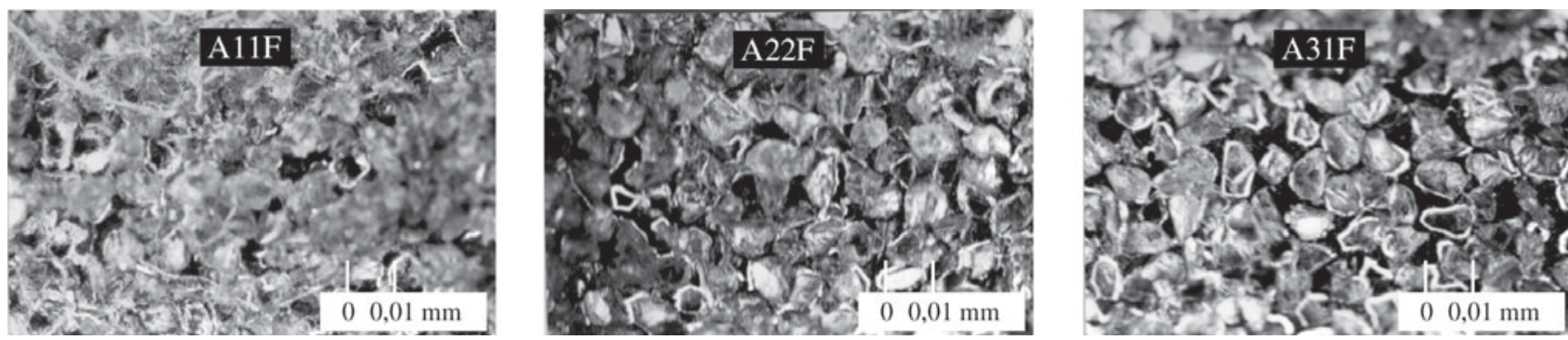

Figura 6. Superfície da ponta usinada após a realização dos ensaios, após uma, duas e três esterilizações em autoclave, respectivamente.
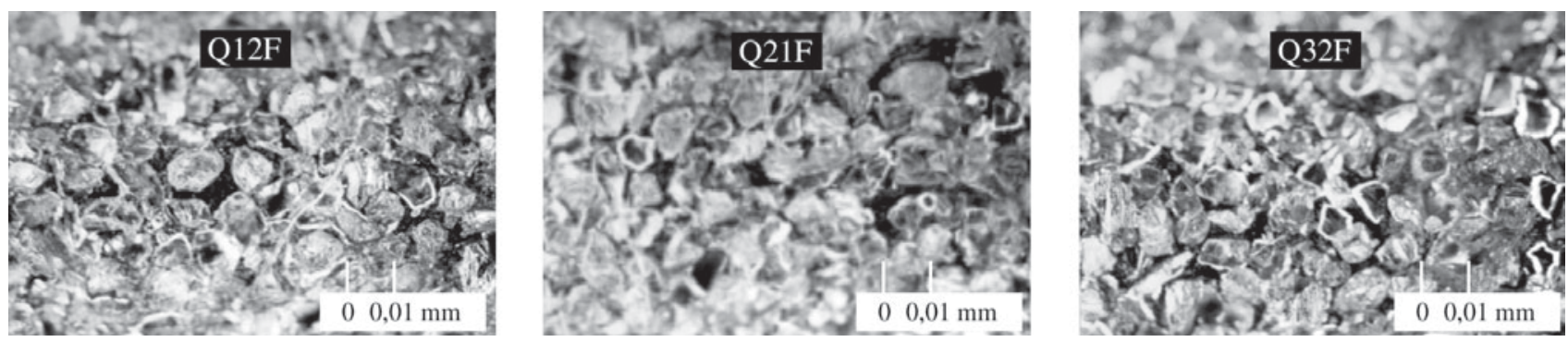

Figura 7. Superfície da ponta usinada após a realização dos ensaios, após uma, duas e três esterilizações por glutaraldeído, respectivamente. 
e, dessa forma, sofreram mais os efeitos da corrosão. Notase também que os grãos de diamante forma arrancados sem que a camada de níquel apresentasse grande deformação devido a esse arrancamento, como já havia sido observado nas pontas que sofreram esterilização em autoclave, as quais também sofreram corrosão.

A corrosão provocada pelos processos de esterilização em autoclave e esterilização química já havia sido citada em bibliografias anteriores, conforme se apresenta em Zettlemoyer, T.L. et alli (1989), Lester, K.S. et al. (1990) e Napier, BWD et al. (1997).

\section{Conclusões}

As pontas diamantadas submetidas a diferentes processos e ciclos de esterilização apresentam variações significativas na capacidade de corte.

Nota-se que as pontas diamantadas submetidas ao processo de esterilização em estufa apresentaram sempre o melhor desempenho de corte. Destacando-se, ainda, que até a segunda esterilização em estufa, todas as pontas diamantadas ensaiadas apresentaram melhor desempenho de corte que pontas não submetidas a nenhum processo de esterilização. Ou seja, a esterilização em estufa proporcionou à ponta diamantada um aumento da capacidade de remoção de material.

As pontas diamantadas submetidas ao processo de esterilização em autoclave ou esterilização química sofreram corrosão. Com a corrosão houve perda de grãos de diamante ainda no início da usinagem, acarretando em queda no desempenho de corte e rápida elevação da força tangencial de corte, encerrando o ensaio.

Porém, indica a bibliografia que o processo de esterilização em estufa deve seguir critérios rigorosos de segurança e pré-limpeza dos instrumentos a serem esterilizados, a fim de retirar incrustações de tecidos humanos. O processo de esterilização química também exige cuidadosa operação de pré-limpeza.

A esterilização em autoclave exige uma pré-limpeza menos apurada, porém esse processo de esterilização demonstrou-se extremamente prejudicial à capacidade de corte das pontas diamantadas.

Dessa forma, considerando-se apenas o desempenho de corte como fator de escolha, o processo de esterilização em estufa é o melhor processo de esterilização para pontas diamantadas, pois demonstrou menor comprometimento à capacidade de corte das pontas diamantadas e, após a primeira e até uma segunda esterilização, possibilitou até mesmo um aumento do desempenho de corte em relação ao grupo de controle.

\section{Referências}

1. Aguiar, P.R.; Rotta, I. A simulação da máquina de corrente contínua a partir da determinação dos parâmetros método não convencional. IV Congresso Latino Americano de Control Automático - Puebla, México, p. 946950, novembro de 1990.

2. Coordenação de Controle de Infecção Hospitalar, Processamento de Artigos e Superfícies em Estabelecimentos de Saúde, Ministério da Saúde, Brasil, 1994.

3. Corrêa, G.M. et al. Manual Prático para Procedimento de Esterilização e Desifecção em Odontologia, USP, 1994.

4. FOB,-Manual de Biossegurança, http: //www.fob.usp.br/ adm/comissoes/bioseg/manual.htm, Faculdade de Odontologia de Bauru, USP, 2000.

5. Lester, K.L.E., Mitchell, P.T. An Evaluation by Scanning Electron Microscopy of Small Dental Cutting Instruments Through Use and Clean, Australian Dental Journal, 1990.

6. Marques, A.L.V. Curso de Biossegurança (área odontológica) - Associação Brasileira de Odontologia (ABO), 1997.

7. Napier, B.W.D. e Senatore, R.U. They do clean burs.....don't they? Practitioner's Corner, 1997.

8. Vaz, J.C.; Steagall, L.; Issao, M. Eficiência de instrumentos de diamante no desgaste do esmalte de dentes humanos e vidro. Ensaio preliminar com instrumentos nacionais e estrangeiros., Rev. Ass. Paul. Cirurg. Dent., v. 35, n. 1, p. 82 a 91, jan/fev 1981.

9. Zanon, U. Esterilização, desinfecção e anti-sepsia. in: Ferraz, E.M. Manual de Controle de Infecção em Cirurgia, EPU, 1982.

10. Zettlemoyer et ali. Effects of Sterilization Procedures on the Cutting Efficiency on Stainless Steel and Carbon Steel Gates Glidden Drills, Journal of Endodontics, n. $11,1989$. 